\title{
Clinical outcome after bioprosthetic aortic root replacement: A Meta-Analysis and Microsimulation model
}

\author{
Bardia Arabkhani ${ }^{1}$ \\ ${ }^{1}$ Leiden University Medical Center
}

February 18, 2021

\begin{abstract}
Background and aim of the study This study aims to provide an overview of clinical outcome after bioprosthetic aortic root replacement and lifetime event-risk estimates of mortality and valve-related events, and the potential effect of type of prosthesis used. Methods A systematic literature search was conducted between January 2000 and August 2019. Inclusion criteria: aortic root replacement in adults. Data were pooled by inverse-variance weighting and entered a microsimulation model to calculate lifetime event-risk and (event-free) life expectancy. Results Of 2,106 publications, 31 were included ( $\mathrm{N}=5,227$ patients, $74 \%$ stentless valves). Mean age was 65.4 years (74\% male). Pooled early mortality was 5.5\% (95\% CI: 4.3-7.2\%). During follow-up (mean 4.1 years, total 22.706 patient-years), late mortality was $4.8 \%$ patient-year and reoperation $0.9 \% /$ patientyear. Linearized-occurrence-rates for thromboembolism, endocarditis, and hemorrhagic events:1.2; 0.9 and $0.5 \% /$ patient-year; no significant difference between stented and stentless prosthesis. Translating into a 60-year-old patient, an estimated life expectancy of 14 years (general population: 22 years) and lifetime risks of thromboembolism, endocarditis and reintervention of $21 \%, 13 \%$, and $8 \%$, respectively is expected. Conclusions The study shows impaired survival and a notable lifetime risk of valve-related events after bioprosthetic aortic root replacement. The risk of thromboembolism is prominent, especially during earlier follow-up, suggesting higher risk of thromboembolism early after operation. Type of prosthesis, stented or stentless, is not associated with higher valve-related events. Moreover, this study could be used as a benchmark to compare outcome with other aortic root replacement procedures.
\end{abstract}

TITLE: Clinical outcome after bioprosthetic aortic root replacement: A Meta-Analysis and Microsimulation model

Running title: Bioprosthetic aortic root replacement

Bardia Arabkhani MD, PHD ${ }^{1,2}$, Jonathan RG Etnel $\mathrm{MD}^{1}$, Michiel Vriesendorp MD ${ }^{2}$, Richard van Valen MA, PHD ${ }^{1}$, Emmanuel Lansac MD, $\mathrm{PhD}^{3}$, Thomas J. van Brakel MD, PhD ${ }^{2}$, Ad JJC Bogers MD, $\mathrm{PhD}^{1}$, Johanna JM Takkenberg MD, $\mathrm{PhD}^{1}$

${ }^{1}$ Erasmus University Medical Center, Rotterdam, The Netherlands; ${ }^{2}$ Leiden University Medical Center, The Netherlands ${ }^{3}$ Institut Mutualiste Montsouris, Paris, France

* Address for correspondence

B. Arabkhani

E-mail: b.arabkhani@lumc.nl Postal address:

Department of Cardio-Thoracic Surgery, D-06-13

Leiden University Medical Centre

Albinusdreef 2, 2333 ZA Leiden, The Netherlands 
Tel.: 0031715264022

Keywords: Aortic root, Biological valve, Bioprostheses, Bio-Bentall, Stented, Stentless

Abstract: 241

Text and references: 5,816

No funding

\section{ABSTRACT}

Background and aim of the study This study aims to provide an overview of clinical outcome after bioprosthetic aortic root replacement and lifetime event-risk estimates of mortality and valve-related events, and the potential effect of type of prosthesis used.

\section{Methods}

A systematic literature search was conducted between January 2000 and August 2019. Inclusion criteria: aortic root replacement in adults. Data were pooled by inverse-variance weighting and entered a microsimulation model to calculate lifetime event-risk and (event-free) life expectancy.

Results

Of 2,106 publications, 31 were included ( $\mathrm{N}=5,227$ patients, $74 \%$ stentless valves). Mean age was 65.4 years (74\% male). Pooled early mortality was 5.5\% (95\% CI: 4.3-7.2\%). During follow-up (mean 4.1 years, total 22.706 patient-years), late mortality was $4.8 \%$ /patient-year and reoperation $0.9 \%$ /patient-year. Linearizedoccurrence-rates for thromboembolism, endocarditis, and hemorrhagic events: $1.2 ; 0.9$ and $0.5 \%$ /patient-year; no significant difference between stented and stentless prosthesis. Translating into a 60 -year-old patient, an estimated life expectancy of 14 years (general population: 22 years) and lifetime risks of thromboembolism, endocarditis and reintervention of $21 \%, 13 \%$, and $8 \%$, respectively is expected.

\section{Conclusions}

The study shows impaired survival and a notable lifetime risk of valve-related events after bioprosthetic aortic root replacement. The risk of thromboembolism is prominent, especially during earlier follow-up, suggesting higher risk of thromboembolism early after operation. Type of prosthesis, stented or stentless, is not associated with higher valve-related events. Moreover, this study could be used as a benchmark to compare outcome with other aortic root replacement procedures.

\section{Background and aim of the study}

In young patients with aortic root disease, composite mechanical graft replacement - Bentall-procedure- (1) is widely used due to its long-term durability (2). In elderly, biological aortic root replacement is more common, because reoperations are less prominent due to shorter life-expectancy and less structural valve degeneration (SVD) $(3,4)$. This age 'turning-point' however is arbitrary and biological valves are increasingly implanted in middle-aged patients recently. Interestingly, there are no large studies presenting outcome after bioprosthetic aortic root replacement and our knowledge is mainly based on data reported on aortic valve replacement. Additionally, most published studies have limited follow-up duration, which is a limitation for the interpretation of the results, particularly regarding SVD and reoperation hazard (5). Moreover, it is not known how a stentless biological valve prosthesis compares to stented prosthesis with regard to durability and valve-related outcome (6). Stentless valves may have hemodynamic advantages, especially in smaller aortic annulus, however, survival and long-term durability have not yet been proved (7).

Conspicuously, transcatheter aortic valve implantation (TAVI) procedures are gaining ground and with satisfying results, indicating that surgical aortic valve replacement will probably become limited in the near future (8). Nevertheless, when the aortic root is affected and should be replaced, surgery is still the only solution. To provide comprehensive data on outcome after bioprosthetic aortic root replacement and the possible effect of the type of prosthesis, we conducted a systematic review of observational reports on patient 
characteristics and valve-related morbidity, mortality and reintervention with both stented and stentless prostheses and explored potential determinants of outcome.

\section{Materials and methods}

\section{Search Strategy}

On 30 August 2019, a systematic literature search was conducted in MEDLINE, Embase, The Cochrane Collaboration and Web of Science, and Google Scholar (Supplementary file 1). Studies published from January 2000 onwards were screened by two independent reviewers (BA, RvV) using the following inclusion criteria: reporting morbidity and mortality after bioprosthetic aortic root replacement with stentless (no homografts) or stented prosthesis, cohorts [?] 50 patients (to prevent including early experience reports highlighting the learning curve), and mean age at surgery [?] 18 years. Exclusion criteria were: $>25 \%$ acute type A aortic dissection, studies limited to reintervention or mechanical valve prosthesis, studies reporting only early results, $>10 \%$ use of subcoronary technique, $>50 \%$ children included (aged $<18$ years), and state of the art, case reports, experimental studies and reviews. In case the same cohort was published more than once, the most complete publication was selected. All included studies were cross-referenced to identify additional publications. In case of disagreement, studies were assessed by another, independent reviewer (MV) and agreement was negotiated until consensus was reached.

\section{Data Extraction}

Data extraction was performed in duplicate with Microsoft Excel (Microsoft Office 2010, Microsoft, Redmond, WA, USA) by two of the authors (BA and JE) according to the guidelines for reporting mortality and morbidity after cardiac valve interventions (9). Events were not included in our database when adherence to the reporting guidelines could not be ascertained. For each article with missing information on important variables, the corresponding author was requested to provide the missing data. Institutional review board approval was not applicable for this study, and informed consent was waived. An overview of extracted variables is presented in Supplementary file 2.

\section{Data Analysis}

Data analysis was performed with Microsoft Excel (Microsoft Office 2010, Microsoft, Redmond, WA, USA) and IBM SPSS version 21.0 (IBM, Somers, NY, USA) and in the R statistical software (version 3.1.0. R Development Core Team, R Foundation for Statistical Computing, Vienna, Austria) using the metaphor package. Pooled baseline patient characteristics were calculated with the use of sample-size weighting. Early mortality and linearized occurrence rates (LOR) of late valve-related complications were pooled on a logarithmic scale with the use of inverse variance weighting in a random-effects model. Reported study characteristics and pre- and peri-operative patient characteristics are presented as mean +- standard deviation for continuous variables and percentages for discrete variables. For outcome variables, individual and pooled statistics are presented as LOR and 95\% confidence interval (CI). In studies where median and ranges instead of mean and variance were reported, the method described by Hozo et al. (10) was used to calculate the mean. In case of absence of total number of patient-years, this was calculated by multiplying the number of patients with the mean follow-up duration in years. In case a certain event did not occur in an individual study, we assumed that 0.5 events occurred for that particular outcome for the purpose of inverse variance weighting. When an event was not reported, this study was excluded from the analysis of that event. For late mortality and reintervention, subgroup analyses were performed stratifying the root replacement by prosthesis type (stented vs. stentless), follow-up duration (individual study mean follow-up less than pooled mean follow-up versus individual study mean follow-up more than pooled mean follow-up), and age at surgery. To assess the association of these variables with late mortality and reintervention rates, linear regression analyses were performed with weighting the studies according to the inverse variance of the occurrence rate. Heterogeneity between the studies was assessed using the $\mathrm{I}^{2}$ test. Funnels plots were used to investigate publication bias. To investigate the potential influence of publication bias on pooled outcome, sensitivity analyses were conducted by temporarily excluding the smallest quartile (by sample size) of included studies. This systematic review and meta-analysis was conducted according to the PRISMA guidelines (11). 


\section{Microsimulation model: the concept}

The microsimulation model is a computer application that simulates the life of a patient after aortic valve replacement, considering the morbidity and mortality events that the patient could experience. The calculated mortality of a patient is composed of the background mortality of the general population, operative mortality, mortality due to valve-related events and an additional "excess mortality". This so-called excess mortality in the patient compared to a matched person in the general population reflects mortality associated with the underlying left ventricular function, valve pathology, and the root replacement procedure. All pooled and weighted occurrence rates of (operative) mortality risk, the occurrence rate of valve-related events together with the risk of mortality and reintervention directly due to valve-related events were obtained from the meta-analysis. The occurrence rates of all events were assumed to be linear and non-age dependent.

For patients aged 61-70 and > 70 years, these "excess mortality" hazard ratios were 1.2 and 0.8 for males, and 2.2 and 1.3 for females, respectively. The background mortality of the general population was obtained from the 2004 United States Life Tables, as 2004 was the pooled median year of intervention, assuming a constant incidence rate over time in each study (12).

To obtain age-specific estimates of life expectancy and lifetime risk of valve-related morbidity, the microsimulation model was run for the ages of 60,65 and 70 years for 10,000 iterations each and separately for males and females. The age-specific outcomes of both genders were then pooled at the male/female ratio obtained from our meta-analysis. For the internal validation of the model, we performed an additional run for 10,000 iterations at the pooled mean age (65.5 years) and male/female ratio (70\%) of the meta-analysis. The actuarial survival obtained from the microsimulation model for these data was then plotted against the pooled (overall) mortality observed in the meta-analysis. A more detailed account of the microsimulation and the methodology has been supplied previously (13).

ResultsStudy and baseline patient characteristics The initial literature search exposed 2,106 publications. The selection procedure is illustrated in Figure 1. Cross-referencing did not result in additional papers. Thirty-one studies were finally included in this systematic review with a total number of 5,227 patients, mean follow-up of 4.1 years (range 1-10 years), and total follow-up of 22,706 patient-years. Root replacements was performed with a stented prosthesis in $26 \%$ of patients and $74 \%$ were stentless valve prostheses. In one study the implantation period was missing, which was provided by the authors (14). Supplementary file 3 shows an overview of the included publications and study characteristics. Pooled pre- and peri-operative characteristics are presented in Table 1.

\section{Pooled outcome}

Early (30 day) mortality occurred in 339 patients, corresponding to a weighted early mortality of $5.5 \%$ (95\% CI: $4.3-7.1 \%)$. The linearized occurrence rates (LOR) of mortality, reintervention on the aortic root, hemorrhage, thromboembolism, endocarditis and major adverse valve-related events are presented along with a measure of statistical heterogeneity in Table 2 .

Late mortality occurred in 1,037 patients (4.6\%/patient-year); in $41 \%$ the cause was unknown or not reported. The main cause of late mortality was cardiac $(52 \%)$, of these were $51 \%$ valve-related and $49 \%$ non-valverelated cardiac death.

Publication Bias Analysis of the funnel plots revealed evidence of underreporting of late mortality, reintervention on the aortic root, and thromboembolism in studies with smaller patient numbers. For other variables, no evidence of publication bias was found (Supplementary file 3).

Sensitivity analyses revealed that this potential publication bias did not have a substantial effect on pooled outcomes, as these remained generally unchanged after temporary exclusion of smallest quartile of the studies.

\section{Type of prosthesis}

Twenty-tree studies reported using solely a biological valve-containing prosthesis (14-36): 13 studies with Freestyle bioprostheses, 3 Shelhigh bioconduit, 2 studies Bio-Valsalva prosthesis, 1 Edwards S prima Plus, 
2 with mixed stentless prosthesis. In one study the type of the biological valve was unspecified (37). Two studies included both stentless and stented bioprostheses (38, 39). Five studies used (almost) exclusively self-made aortic root prosthesis using a stented bioprostheses (bio-Bentall) to replace the aortic root. (40-44).

No associations were found between late mortality or reintervention, and the type of prosthesis used. Table 3 shows detailed information on valve-related outcome for "stentless" and "stented" subgroups.Duration of follow-up

A subgroup analysis was performed with 12 studies with a mean follow-up of at least 5 years pooled weighted mean of 7.4 years (range 5.0 to 10.1 years) with a pooled mean age of 65.9 years, and compared to the other 19 studies, with a mean follow-up of 2.56 years (1.0 to 4.8 years) and pooled mean age of 65.8 were analyzed. Table 4 shows details on outcome.

Microsimulation predictions of age-specific life expectancy and outcomeMicrosimulation-based estimates of life expectancy and lifetime risk of valve-related morbidity for 60, 65 and 70 years old patients are shown in Figure 2. The microsimulation model calibration with the pooled mortality is shown is Supplementary file 4 .

\section{Conclusions}

This study provides an overview of contemporary published studies on outcome after aortic root replacement with biological valve prostheses and provides age-specific prediction of valve-related outcome. Patient survival is impaired. Type of prosthesis is not associated with (valve-related) outcome. Notably, thromboembolic events occur frequent, especially during early follow-up. This report may be used to benchmark the potential therapeutic benefit of other surgical approaches.

\section{Early mortality}

The observed pooled early mortality was $5.5 \%$. This is in accordance with an older review on aortic root replacement (4.5 to 5.3\%) and with the recent report of the Society of Thoracic Surgeons database from the U.S. that estimates early mortality after bioprosthetic aortic root replacement to be $6.2 \%(45,46)$. However, these studies include also acute and emergent operative indication like endocarditis and aortic dissection. Early mortality was mainly due to low cardiac output $(22.7 \%)$ and multi-organ failure (18.1\%). Surgical indication was endocarditis in $9.2 \%$ of patients and type A aortic dissection in $7.2 \%$. The high mortality could (partly) be explained by operation in emergent setting and partly by the additional procedures (e.g. arch replacement, CABG). Nevertheless, overall early mortality seems not changed significantly last 2 decades.

Late mortality and reintervention outcome There was a high mortality rate (4.8\%/pt-year) for a pooled mean age of 65.9 years, which is higher than the general population mortality. Translated to our microsimulationbased life-expectancy, there is a life-expectancy of 14.3 year for a 60 year old patient receiving a bioprosthetic root replacement, while there is a life-expectancy of 22.5 years for the 60 year old U.S. "healthy" population (12). From previous research there is evidence of significant "excess mortality" in (elective) isolated aortic valve replacement, compared to the age-matched general population (47). Additionally, patients in this study were diagnosed with a dilated aortic root as well, with about $13 \%$ suffering from a dissection of the root and/or connective tissue disease, which are conditions that may influence patient survival due to complication other than valve-related events.

This microsimulation model shows a life-time reintervention risk of $9 \%$ for patients older than 60 years, which is comparable to previous predictions on biological aortic valve prostheses (3). It is known that younger patients, especially younger than 60 years, are more likely to have a reintervention after biological aortic valve replacement, mainly due to progressive $\operatorname{SVD}(3,48)$. Of the 8 studies that explicitly tested association between age and reintervention, 3 found indeed that older age is associated with lower reintervention hazard.

Thromboembolic events We found a high incidence of thromboembolic events, with a life-time risk of more than $20 \%$ after bioprosthetic aortic root replacement. Data on TE events are not comprehensive, thus discriminating between TIA and disabling ischemic CVA is not possible. However, a previous systematic 
review and microsimulation study on aortic valve replacement with isolated biological stented valve, published by Puvimanasinghe et al. (3), reports similar TE event rates (1.4\%/patient-year). Additionally, the incidence of thromboembolic events is known to increase with age $(49,50)$ and might partly explain this high incidence of thromboembolic events.

Subsequently the question arises whether there is a difference with patients receiving a classical Bentall prosthesis. Although this comparison is hampered by the differences in patient characteristics, mainly due to the younger age in patient receiving mechanical valves; a recently published meta-analysis on the Bentall procedure (mean age 50 years), shows lower thromboembolic event rates (0.77\%/patient-year) (51). Another study on mechanical valve replacement in non-elderly showed suboptimal survival and considerable lifetime risk of anticoagulation-related complications (52). However, the anticoagulation therapy after mechanical valve implantation in these patients plays a protective role in prevention of thromboembolic events, as it also occurs irrespective of the aortic valve replacement due to the aging process (50).

Additionally, TE hazard is less likely to occur during long-term follow-up, suggesting a larger hazard in the early postoperative period, which may be related to anticoagulation therapy. There were also some studies that included (a small portion of) patients diagnosed with endocarditis and aortic dissection, which may have led to additional TE rate. However, excluding these studies from the analysis did not changed the results. According to the current US and European guidelines on the management of valvular heart disease, antiplatelet therapy is reasonable and may be considered for the first 3 months after biological valve replacement $(2,53)$. Additionally, the European guidelines state that the need for a 3 months postoperative period of anticoagulation therapy has been challenged in patients with bioprostheses, with low-dose aspirin being favored as an alternative.

Hence, it is questionable whether the proposed anticoagulation therapy is appropriate in patient receiving a bioprosthetic aortic root replacement. Nevertheless, due to a lack of data on the exact anticoagulation therapy and patient compliance, it is not possible to make broad inference about this possible association. Further studies are needed to determine the most optimal anticoagulation therapy after biological aortic valve replacement.Endocarditis and type of prostheses Although the rate of endocarditis after bioprosthetic aortic root replacement varies widely in the literature (54), our findings are comparable to an older study on biological aortic valve replacement [3]. Nine studies included patients with acute endocarditis, of which three with an endocarditis rate of more than $2.8 \%$ /patient-year $(22,26,55)$, all including stentless valve prostheses. However, these studies included a relatively high proportion of patients with active endocarditis which may explain the higher re-endocarditis rate, although the severity of endocarditis was not provided. Hence, the trend toward more endocarditis in stentless valves could possibly be explained by the latter. Based on these data it is reasonable to assume that stented bioprosthetic grafts are at least not inferior to stentless bioprosthetic grafts to be used in case of endocarditis, although the extent of endocarditis may allow for different inference. Moreover, we found no difference in other valve-related events between stentless and stented prosthesis. We believe that both prostheses are safe to use in the average patient undergoing aortic root replacement.

\section{The position of bioprosthetic aortic root replacement}

There is no perfect valve substitute for the individual patient with aortic valve and/or root disease as all prostheses are associated with certain valve-related events of varying nature. Careful weighting of the advantages and disadvantages of biological and mechanical valve substitutes tailored to the patient's unique characteristics and preferences, is the current gold standard. Interestingly, there is a trend toward using a biological valve in younger patients $(5,56)$. Although evidence is lacking, perhaps this is emerging due to the potential prospect of transcatheter valve-in-valve therapy as a future solution for bioprosthetic SVD.

According to the ESC/EACTS guidelines on valvular heart disease, age limits contain an arbitrary element, and the choice of prostheses type should be individualized in a joint decision between the patient and doctor. Although SVD is known to occur earlier in younger patients (57), mechanical valve prostheses are not the preferred alternative in all young patients. Nevertheless, as individual patient norms, values and goals in life 
vary widely, the decision for a particular valve prosthesis should be individualized in a shared decision making process, and together with surgical experience, the most suitable surgical approach should be determined $(2$, 53). Our systematic review adds to the body of evidence by showing in a middle-aged patient population, undergoing bioprosthetic aortic root replacement, acceptable reintervention rates and valve-related event occurrence, and may be used as a benchmark to compare outcome with other type of prosthesis, e.g. Bentall and valve-sparing procedures.

Limitations As in all systematic reviews and meta-analysis of retrospective observational studies, limitations of this type of study should be taken into consideration (58). Furthermore, recall bias inherent to the retrospective design of all but one study and publication bias may have affected the observed outcome. In addition, the included studies represent a heterogeneous population of patients with different patient characteristics, with patients operated in different era spanning over 20 years, and considering improvements in anticoagulation strategies, medical management of valvular heart disease and surgical techniques over the past decades, which may have influenced outcome. Moreover, a lack of uniform data reporting as proposed by the guidelines (9) may have influenced the uniformity of the pooled data.

The pooled late outcome estimates are based on the linearity assumption, while occurrence of outcome events may not be linear in nature. However, due to the lack of randomized trials where homogeneous data are present, this meta-analysis was performed to provide an overview of published outcomes after bioprosthetic aortic root replacement.

\section{Conclusion}

This study provides an overview of contemporary outcome after bioprosthetic aortic root replacement and demonstrates impaired survival and notable valve-related events, irrespective of the type of valve prosthesis. Thromboembolic events occur relatively frequent and may be associated with higher thrombogenicity of the biological valve, at least in the early postoperative period. This should be considered when choosing the most optimal treatment, especially in younger patients. Given the observed heterogeneity of the pooled study results, in-depth analysis of potential risk factors remains challenging. It requires a collective international effort employing uniform data definitions and high quality data collection, to push forward the knowledge on outcomes and provide clues toward optimization of treatment selection for patients requiring aortic root replacement (59). Nevertheless, this study provides comprehensive outcome and may be used as a benchmark to compare with other types of procedures (e.g. Bentall or valve-sparing procedures).

Data availability statementThe data that support the findings of this study are available at PubMed, at https://pubmed.ncbi.nlm.nih.gov, references are the studies included into this systematic review. These data were derived from the following resources available in the public domain: MEDLINE (PubMed), Embase, The Cochrane Collaboration and Web of Science, and Google Scholar.

\section{Reference}

1. Bentall H, De Bono A. A technique for complete replacement of the ascending aorta. Thorax. 1968;23(4):338-9.

2. Vahanian A, Alfieri O, Andreotti F, Antunes MJ, Baron-Esquivias G, Baumgartner H, et al. Guidelines on the management of valvular heart disease (version 2012): the Joint Task Force on the Management of Valvular Heart Disease of the European Society of Cardiology (ESC) and the European Association for Cardio-Thoracic Surgery (EACTS). Eur J Cardiothorac Surg. 2012;42(4):S1-44.

3. Puvimanasinghe JP, Takkenberg JJ, Eijkemans MJ, Steyerberg EW, van Herwerden LA, Grunkemeier GL, et al. Prognosis after aortic valve replacement with the Carpentier-Edwards pericardial valve: use of microsimulation. Ann Thorac Surg. 2005;80(3):825-31.

4. Johnston DR, Soltesz EG, Vakil N, Rajeswaran J, Roselli EE, Sabik JF, 3rd, et al. Long-term durability of bioprosthetic aortic valves: implications from 12,569 implants. Ann Thorac Surg. 2015;99(4):1239-47. 
5. Dunning J, Gao H, Chambers J, Moat N, Murphy G, Pagano D, et al. Aortic valve surgery: marked increases in volume and significant decreases in mechanical valve use-an analysis of 41,227 patients over 5 years from the Society for Cardiothoracic Surgery in Great Britain and Ireland National database. J Thorac Cardiovasc Surg. 2011;142(4):776-82 e3.

6. de Kerchove L, Glineur D, El Khoury G, Noirhomme P. Stentless valves for aortic valve replacement: where do we stand? Curr Opin Cardiol. 2007;22(2):96-103.

7. Dunning J, Graham RJ, Thambyrajah J, Stewart MJ, Kendall SW, Hunter S. Stentless vs. stented aortic valve bioprostheses: a prospective randomized controlled trial. Eur Heart J. 2007;28(19):2369-74.

8. Mack MJ, Leon MB, Thourani VH, Makkar R, Kodali SK, Russo M, et al. Transcatheter Aortic-Valve Replacement with a Balloon-Expandable Valve in Low-Risk Patients. N Engl J Med. 2019;380(18):1695-705.

9. Akins CW, Miller DC, Turina MI, Kouchoukos NT, Blackstone EH, Grunkemeier GL, et al. Guidelines for reporting mortality and morbidity after cardiac valve interventions. Ann Thorac Surg. 2008;85(4):1490-5.

10. Hozo SP, Djulbegovic B, Hozo I. Estimating the mean and variance from the median, range, and the size of a sample. BMC Med Res Methodol. 2005;5:13.

11. Beller EM, Glasziou PP, Altman DG, Hopewell S, Bastian H, Chalmers I, et al. PRISMA for Abstracts: reporting systematic reviews in journal and conference abstracts. PLoS Med. 2013;10(4):e1001419.

12. Arias E. United States life tables, 2004. Natl Vital Stat Rep. 2007;56(9):1-39.

13. Takkenberg JJ, Puvimanasinghe JP, Grunkemeier GL. Simulation models to predict outcome after aortic valve replacement. Ann Thorac Surg. 2003;75(5):1372-6.

14. Melina G, De Robertis F, Gaer JA, Amrani M, Khaghani A, Yacoub MH. Mid-term pattern of survival, hemodynamic performance and rate of complications after medtronic freestyle versus homograft full aortic root replacement: results from a prospective randomized trial. J Heart Valve Dis. 2004;13(6):972-5; discussion 5-6.

15. Kon ND, Riley RD, Adair SM, Kitzman DW, Cordell AR. Eight-year results of aortic root replacement with the freestyle stentless porcine aortic root bioprosthesis. Ann Thorac Surg. 2002;73(6):1817-21.

16. Auriemma S, D'Onofrio A, Brunelli M, Magagna P, Paccanaro M, Rulfo F, et al. Long-term results of aortic valve replacement with Edwards Prima plus stentless bioprosthesis: Eleven years' follow up. J Heart Valve Dis. 2006;15(5):691-5.

17. Dapunt OE, Easo J, Holzl PP, Murin P, Sudkamp M, Horst M, et al. Stentless full root bioprosthesis in surgery for complex aortic valve-ascending aortic disease: a single center experience of over 300 patients. Eur J Cardiothorac Surg. 2008;33(4):554-9.

18. LeMaire SA, Green SY, Sharma K, Cheung CK, Sameri A, Tsai PI, et al. Aortic Root Replacement With Stentless Porcine Xenografts: Early and Late Outcomes in 132 Patients. Annals of Thoracic Surgery. 2009;87(2):503-13.

19. Zannis K, Deux JF, Tzvetkov B, Nakashima K, Loisance D, Rahmouni A, et al. Composite Freestyle Stentless Xenograft With Dacron Graft Extension for Ascending Aortic Replacement. Ann Thorac Surg. 2009;87(6):1789-94.

20. Baraki H, Al Ahmad A, Sarikouch S, Koigeldiev N, Khaladj N, Hagl C, et al. The First Fifty Consecutive Bentall Operations with a Prefabricated Tissue-Valved Aortic Conduit: A Single-Center Experience. Journal of Heart Valve Disease. 2010;19(3):286-91.

21. El-Hamamsy I, Clark L, Stevens LM, Sarang Z, Melina G, Takkenberg JJM, et al. Late Outcomes Following Freestyle Versus Homograft Aortic Root Replacement. Results From a Prospective Randomized Trial. J Am Coll Cardiol. 2010;55(4):368-76. 
22. Desai ND, McCarthy F, Moser W, Szeto WY, Zeeshan A, Brown D, et al. Durability of porcine bioroots in younger patients with aortic root pathology: A propensity-matched comparison with composite mechanical roots. Ann Thorac Surg. 2011;92(6):2054-61.

23. Ennker IC, Albert A, Dalladaku F, Rosendahl U, Ennker J, Florath I. Midterm outcome after aortic root replacement with stentless porcine bioprostheses. Eur J Cardio-thorac Surg. 2011;40(2):429-34.

24. Galinanes M, Meduoye A, Ferreira I, Sosnowski A. Totally biological composite aortic stentless valved conduit for aortic root replacement: 10-year experience. J Cardiothorac Surg. 2011;6:86.

25. Kaya A, Heijmen RH, Kelder JC, Schepens MA, Morshuis WJ. Stentless biological valved conduit for aortic root replacement: Initial experience with the Shelhigh BioConduit model NR-2000C. J Thorac Cardiovasc Surg. 2011;141(5):1157-62.

26. Kaya A, Heijmen RH, Kelder JC, Morshuis WJ. First 102 patients with the biovalsalva conduit for aortic root replacement. Ann Thorac Surg. 2012;94(1):72-7.

27. Lehr EJ, Wang PZT, Oreopoulos A, Kanji H, Norris C, MacArthur R. Midterm outcomes and quality of life of aortic root replacement: Mechanical vs biological conduits. Can J Cardiol. 2011;27(2):262.e15-.e20.

28. Pagni S, Slater AD, Trivedi JR, Williams M, Austin E, Mascio CE, et al. Proximal Thoracic Aortic Replacement for Aneurysmal Disease Using the Freestyle Stentless Bioprosthesis: A 10-Year Experience. Annals of Thoracic Surgery. 2011;92(3):873-9.

29. Bach DS, Kon ND. Long-term clinical outcomes 15 years after aortic valve replacement with the freestyle stentless aortic bioprosthesis. Ann Thorac Surg. 2014;97(2):544-51.

30. Meszaros K, Liniger S, Czerny M, Stanger O, Reineke D, Englberger L, et al. Mid-term results of aortic root replacement using a self-assembled biological composite graft. Interact Cardiovasc Thorac Surg. 2014.

31. Mohammadi S, Kalavrouziotis D, Voisine P, Dumont E, Doyle D, Perron J, et al. Bioprosthetic valve durability after stentless aortic valve replacement: The effect of implantation technique. Ann Thorac Surg. 2014;97(6):2011-8.

32. Benetis R, Bolys R, Jakuska P, Ereminiene E, Jurgaitiene R, Kinduris S, et al. Long-term clinical and hemodynamic outcomes after operations on aortic root using stentless aortic valves. Exp Clin Cardiol. 2014;20(7):307-27.

33. Sherrah AG, Jeremy RW, Puranik R, Bannon PG, Hendel PN, Bayfield MS, et al. Long Term Outcomes Following Freestyle Stentless Aortic Bioprosthesis Implantation: An Australian Experience. Heart Lung Circ. 2016;25(1):82-8.

34. Sahin A, Muggler O, Sromicki J, Caliskan E, Reser D, Emmert MY, et al. Long-term follow-up after aortic root replacement with the Shelhigh(R) biological valved conduit: a word of caution! Eur J Cardiothorac Surg. 2016.

35. Schneider AW, Putter H, Hazekamp MG, Holman ER, Bruggemans EF, Versteegh MIM, et al. Twentyyear experience with stentless biological aortic valve and root replacement: informing patients of risks and benefits. Eur J Cardio-Thorac. 2018;53(6):1272-8.

36. Reineke DC, Kaya A, Heinisch PP, Oezdemir B, Winkler B, Huber C, et al. Long-term follow-up after implantation of the Shelhigh(R) No-React(R) complete biological aortic valved conduit. European journal of cardio-thoracic surgery : official journal of the European Association for Cardio-thoracic Surgery. 2016;50(1):98-104.

37. Svensson LG, Pillai ST, Rajeswaran J, Desai MY, Griffin B, Grimm R, et al. Long-term survival, valve durability, and reoperation for 4 aortic root procedures combined with ascending aorta replacement. J Thorac Cardiovasc Surg. 2016;151(3):764-71 e1-4. 
38. Yang JA, Neely RC, Stewart AS. Modified bentall procedure with composite biologic grafts. J Card Surg. 2013;28(6):731-5.

39. Gleason TG, David TE, Coselli JS, Hammon Jr JW, Bavaria JE. St. Jude medical Toronto biologic aortic root prosthesis: Early FDA phase II IDE study results. Ann Thorac Surg. 2004;78(3):786-93.

40. Etz CD, Bischoff MS, Bodian C, Roder F, Brenner R, Griepp RB, et al. The Bentall procedure: is it the gold standard? A series of 597 consecutive cases. J Thorac Cardiovasc Surg. 2010;140(6 Suppl):S64-70; discussion S86-91.

41. Mazzola A, Di Mauro M, Pellone F, Faragalli F, Villani C, Di Eusanio M, et al. Freestyle aortic root bioprosthesis is a suitable alternative for aortic root replacement in elderly patients: A propensity score study. Ann Thorac Surg. 2012;94(4):1185-90.

42. Badiu CC, Deutsch MA, Bleiziffer S, Krane M, Hettich I, Voss B, et al. Early hemodynamic performance of the BioValsalva valved conduit after aortic root replacement. J Heart Valve Dis. 2014;23(1):97-104.

43. Urbanski PP, Dinstak W, Rents W, Heinz N, Diegeler A. Long-term results after aortic root replacement using self-assembled valve composite grafts in patients with small aortic annulus. Interact Cardiovasc Thorac Surg. 2014;18(2):159-63.

44. Gaudino M, Weltert L, Munjal M, Lau C, Elsayed M, Salica A, et al. Early clinical outcome after aortic root replacement using a biological composite valved graft with and without neo-sinuses. Eur J Cardiothorac Surg. 2017;51(2):316-21.

45. Sherrah AG, Edelman JJ, Thomas SR, Brady PW, Wilson MK, Jeremy RW, et al. The freestyle aortic bioprosthesis: a systematic review. Heart Lung Circ. 2014;23(12):1110-7.

46. Stamou SC, Williams ML, Gunn TM, Hagberg RC, Lobdell KW, Kouchoukos NT. Aortic root surgery in the United States: a report from the Society of Thoracic Surgeons database. J Thorac Cardiovasc Surg. 2015;149(1):116-22 e4.

47. Head SJ, Mokhles MM, Osnabrugge RL, Pibarot P, Mack MJ, Takkenberg JJ, et al. The impact of prosthesis-patient mismatch on long-term survival after aortic valve replacement: a systematic review and meta-analysis of 34 observational studies comprising 27186 patients with 133141 patient-years. Eur Heart J. 2012;33(12):1518-29.

48. Chan V, Malas T, Lapierre H, Boodhwani M, Lam BK, Rubens FD, et al. Reoperation of left heart valve bioprostheses according to age at implantation. Circulation. 2011;124(11 Suppl):S75-80.

49. Yiin GS, Howard DP, Paul NL, Li L, Luengo-Fernandez R, Bull LM, et al. Age-specific incidence, outcome, cost, and projected future burden of atrial fibrillation-related embolic vascular events: a populationbased study. Circulation. 2014;130(15):1236-44.

50. Rothwell PM, Coull AJ, Giles MF, Howard SC, Silver LE, Bull LM, et al. Change in stroke incidence, mortality, case-fatality, severity, and risk factors in Oxfordshire, UK from 1981 to 2004 (Oxford Vascular Study). Lancet. 2004;363(9425):1925-33.

51. Mookhoek A, Korteland NM, Arabkhani B, Di Centa I, Lansac E, Bekkers JA, et al. Bentall Procedure: A Systematic Review and Meta-Analysis. Ann Thorac Surg. 2016.

52. Korteland NM, Etnel JRG, Arabkhani B, Mokhles MM, Mohamad A, Roos-Hesselink JW, et al. Mechanical aortic valve replacement in non-elderly adults: meta-analysis and microsimulation. Eur Heart J. 2017;38(45):3370-7.

53. Nishimura RA, Otto CM, Bonow RO, Carabello BA, Erwin JP, 3rd, Guyton RA, et al. 2014 AHA/ACC guideline for the management of patients with valvular heart disease: a report of the American College of Cardiology/American Heart Association Task Force on Practice Guidelines. J Am Coll Cardiol. 2014;63(22):e57185 . 
54. Sherrah AG, Edelman JJB, Thomas SR, Brady PW, Wilson MK, Jeremy RW, et al. The Freestyle Aortic Bioprosthesis: A Systematic Review. Heart Lung Circul. 2014.

55. Dapunt OE, Easo J, Holzl PPF, Murin P, Sudkamp M, Horst M, et al. Stentless full root bioprosthesis in surgery for complex aortic valve-ascending aortic disease: a single center experience of over 300 patients. European Journal of Cardio-Thoracic Surgery. 2008;33(4):554-8.

56. Head SJ, Kappetein AP. Aortic valve replacement in younger adults: a biological valve is not the logical choice. European heart journal. 2015.

57. Bourguignon T, Bouquiaux-Stablo AL, Candolfi P, Mirza A, Loardi C, May MA, et al. Very long-term outcomes of the Carpentier-Edwards Perimount valve in aortic position. Ann Thorac Surg. 2015;99(3):831-7.

58. Ioannidis JP, Lau J. Pooling research results: benefits and limitations of meta-analysis. Jt Comm J Qual Improv. 1999;25(9):462-9.

59. www.researchonline.org/link/study/aviator. TArdaootiagotcwgoavartA. The AVIATOR registry database: an overview of the intentions and goals of this collaborative working group on aortic valve and root treatment. 2014 [

Tables

Table 1. Pooled pre-operative and peri-operative characteristics.

\begin{tabular}{|c|c|c|c|c|}
\hline Variable & & Pooled data & Range & $\begin{array}{l}\text { Included } \\
\text { studies (N) }\end{array}$ \\
\hline $\begin{array}{l}\text { Total patient } \\
\text { number }\end{array}$ & & 5227 & $50-421$ & 31 \\
\hline Surgical period & & $1992-2014$ & & 30 \\
\hline Mean age & & 65.4 years & $47-73$ years & 30 \\
\hline Gender & Male & $67.6 \%$ & $30-85 \%$ & 31 \\
\hline \multirow[t]{6}{*}{ Etiology } & Valve pathology & & & 18 \\
\hline & Aortic stenosis & $49.8 \%$ & $3-100 \%$ & \\
\hline & $\begin{array}{l}\text { Aortic } \\
\text { regurgitation }\end{array}$ & $37.7 \%$ & $0-92 \%$ & \\
\hline & $\begin{array}{l}\text { Stenosis \& } \\
\text { regurgitation }\end{array}$ & $17.9 \%$ & & \\
\hline & $\begin{array}{l}\text { Connective tissue } \\
\text { disease }\end{array}$ & $2.9 \%$ & $0-32 \%$ & 13 \\
\hline & $\begin{array}{l}\text { Bicuspid aortic } \\
\text { valve }\end{array}$ & $28.0 \%$ & $0-42.6 \%$ & 14 \\
\hline Prior surgery & Cardiac & $14.2 \%$ & $0-39 \%$ & 23 \\
\hline \multirow[t]{2}{*}{ Other indications } & $\begin{array}{l}\text { Acute type A } \\
\text { dissection }\end{array}$ & $7.2 \%$ & $0-24 \%$ & 20 \\
\hline & $\begin{array}{l}\text { Acute } \\
\text { endocarditis }\end{array}$ & $9.1 \%$ & $1-11 \%$ & 9 \\
\hline \multirow[t]{3}{*}{ Valve type } & Stentless & $99.7 \%$ & $95-100 \%$ & 23 \\
\hline & Stented & $92.8 \%$ & $84-100 \%$ & 5 \\
\hline & Mixed & $50 \%$ & $50-50 \%$ & 2 \\
\hline \multirow[t]{4}{*}{$\begin{array}{l}\text { Concomitant } \\
\text { procedures }\end{array}$} & $\begin{array}{l}\text { Aortic hemiarch } \\
\text { repair }\end{array}$ & $18.2 \%$ & $0-44 \%$ & 19 \\
\hline & Aortic arch repair & $5.9 \%$ & $3-21 \%$ & 19 \\
\hline & CABG & $28.9 \%$ & $0-44 \%$ & 19 \\
\hline & $\begin{array}{l}\text { Mitral valve } \\
\text { surgery }\end{array}$ & $3.3 \%$ & $0-17 \%$ & 19 \\
\hline
\end{tabular}




\begin{tabular}{|c|c|c|c|c|}
\hline Variable & & Pooled data & Range & $\begin{array}{l}\text { Included } \\
\text { studies }(\mathrm{N})\end{array}$ \\
\hline $\begin{array}{l}\text { Re-exploration for } \\
\text { bleeding }\end{array}$ & & $10.8 \%$ & $1-28 \%$ & 14 \\
\hline Early mortality & & $5.5 \%$ & $0-16 \%$ & 31 \\
\hline \multirow[t]{4}{*}{$\begin{array}{l}\text { Causes of early } \\
\text { mortality * }\end{array}$} & $\begin{array}{l}\text { Low cardiac } \\
\text { output }\end{array}$ & $22.7 \%$ & $1-44 \%$ & \\
\hline & $\begin{array}{l}\text { Multi-organ failure } \\
\text { Hemorrhage }\end{array}$ & $18.1 \% 7.5 \%$ & $13-100 \% 0-13 \%$ & \\
\hline & $\begin{array}{l}\text { Sepsis Myocardial } \\
\text { infarction }\end{array}$ & $5.0 \% 4.0 \%$ & $6-25 \% 0-100 \%$ & \\
\hline & $\begin{array}{l}\text { Unknown / } \\
\text { unreported }\end{array}$ & $9.6 \%$ & $10-55 \%$ & \\
\hline
\end{tabular}

CABG indicates coronary artery bypass grafting. * major causes of early mortality. Data indicate the pooled mean $\%$ of occurrence and the pooled range of occurrence. Included studies are publications reporting on the specific characteristic. The percentages mentioned are means of the reported variables in the studies that provided these variable numbers. The range indicates the lowest and the highest reported $\%$ of that specific variable within all studies, and $\mathrm{N}$ indicates the number of studies reporting on that specific variable.

Table 2. Linearized occurrence rates of late outcome events.

\begin{tabular}{lllll}
\hline Pooled late outcome events & LOR $(\boldsymbol{\%} / \mathbf{y r})+\mathbf{9 5 \%} \mathbf{C I}^{*}$ & Heterogeneity $\left(\mathbf{I}^{\mathbf{2}}\right)$ & Included studies $(\mathbf{N})$ & Events \\
\hline Late mortality & $\mathbf{4 . 6 1}(3.98-5.36)$ & 71 & 31 & 1037 \\
Root reintervention & $\mathbf{0 . 7 2}(0.47-1.10)$ & 73 & 31 & 167 \\
Hemorrhage & $\mathbf{0 . 5 6}(0.33-0.94)$ & 68 & 27 & 83 \\
Thromboembolism & $\mathbf{1 . 4 1}(0.96-2.06)$ & 73 & 26 & 180 \\
Endocarditis & $\mathbf{0 . 9 4}(0.69-1.32)$ & 69 & 27 & 130 \\
SVD* & $\mathbf{0 . 3 2}(0.16-0.62)$ & 76 & 26 & 74 \\
NSVD* & $\mathbf{0 . 2 1}(0.13-0.34)$ & 49 & 21 & 15 \\
\hline
\end{tabular}

LOR indicates linearized occurrence rates; CI, confidence interval; SVD, structural valve degeneration; MAVRE, major adverse valve-related events. * not all (N)SVD led to reintervention

Table 3. Mortality and valve-related outcome for stentless and stented valve prosthesis.

\begin{tabular}{lllllllll}
\hline & Stentless & Stentless & Stentless & Stentless & Stented & Stented & Stented & Stented \\
\hline & LOR & $\mathbf{9 5 \%}$ CI - & $\mathbf{9 5 \%} \mathbf{C I}+$ & $\mathbf{N}$ & $\mathbf{L O R}$ & $\mathbf{9 5 \%} \mathbf{C I} \mathbf{-}$ & $\mathbf{9 5 \%} \mathbf{C I}+$ & $\mathbf{N}$ \\
Early Mortality & 6.5 & 5.1 & 8.4 & 23 & 5.5 & 4.0 & 7.6 & 5 \\
Late Mortality & 4.9 & 4.2 & 5.6 & 23 & 4.3 & 3.1 & 6.0 & 5 \\
Reintervention & 1.0 & 0.7 & 1.4 & 23 & 0.9 & 0.3 & 2.6 & 5 \\
TE & 1.5 & 1.1 & 2.2 & 20 & 0.5 & 0.2 & 1.4 & 5 \\
Bleeding & 0.3 & 0.2 & 0.6 & 19 & 0.6 & 0.2 & 1.9 & 5 \\
Endocarditis & 1.0 & 0.8 & 1.4 & 22 & 0.4 & 0.2 & 0.8 & 4 \\
SVD & 0.4 & 0.3 & 0.7 & 20 & 0.7 & 0.2 & 3.1 & 5 \\
\hline
\end{tabular}

LOR indicates linearized occurrence rates; CI confidence interval; N number of studies included in analysis Table 4. Mortality and valve-related outcome for mean follow-up (FU) more than 5 years and less than 5 
years.

\begin{tabular}{|c|c|c|c|c|c|c|c|}
\hline & $\mathbf{F U}<5$ yrs & $\mathbf{F U}<5$ yrs & $\mathbf{F U}<5$ yrs & $\mathbf{F U}<5$ yrs & FU $>5$ yrs & FU $>5$ yrs & $\mathbf{F U}>$ \\
\hline & LOR & $95 \%$ CI - & $95 \% \mathrm{CI}+$ & $\mathbf{N}$ & LOR & $95 \%$ CI - & $95 \% \mathrm{C}$ \\
\hline Early Mortality & 6.2 & 4.8 & 8.0 & 18 & 5.7 & 4.5 & 7.2 \\
\hline Late Mortality & 4.4 & 3.5 & 5.6 & 18 & 4.8 & 3.9 & 5.8 \\
\hline Reintervention & 1.2 & 0.7 & 1.9 & 15 & 0.4 & 0.2 & 0.7 \\
\hline TE & 1.6 & 1.0 & 2.5 & 15 & 0.7 & 0.3 & 1.5 \\
\hline Bleeding & 0.6 & 0.3 & 1.3 & 13 & 0.5 & 0.3 & 0.8 \\
\hline Endocarditis & 1.4 & 1.0 & 1.9 & 15 & 0.5 & 0.3 & 0.8 \\
\hline SVD & 0.3 & 0.2 & 0.5 & 12 & 0.3 & 0.2 & 0.5 \\
\hline
\end{tabular}

LOR indicates linearized occurrence rates; CI confidence interval; N number of studies included in analysis

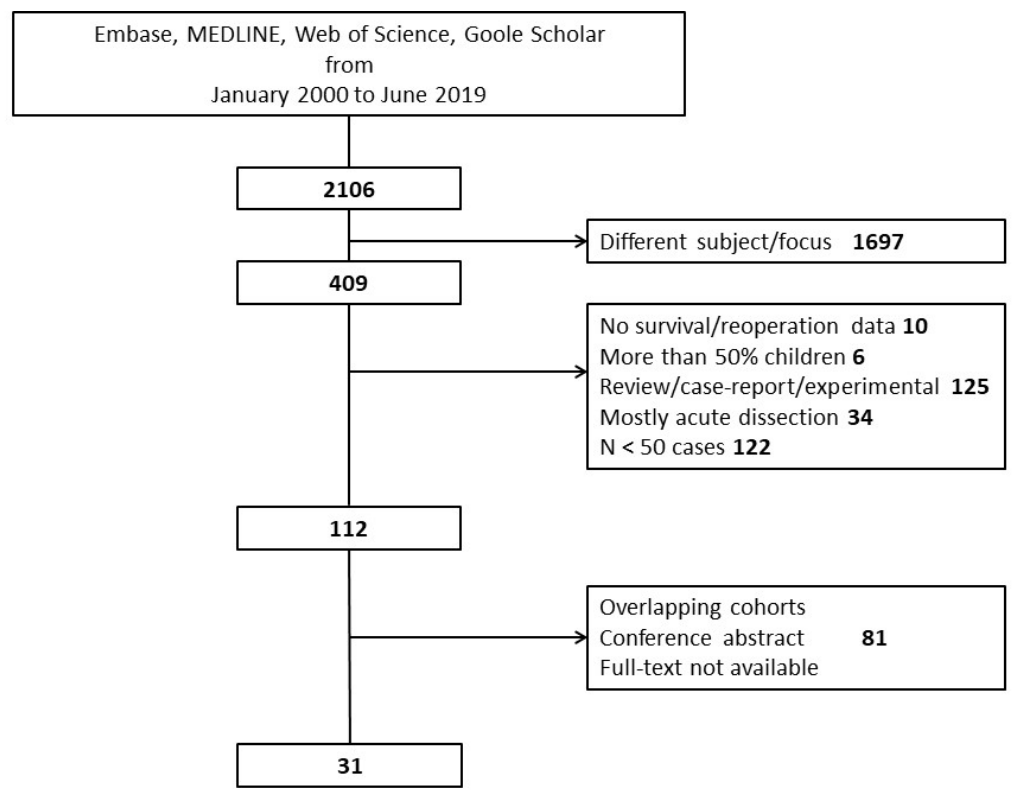

Figure 1. Flowchart of systematic search and included articles 


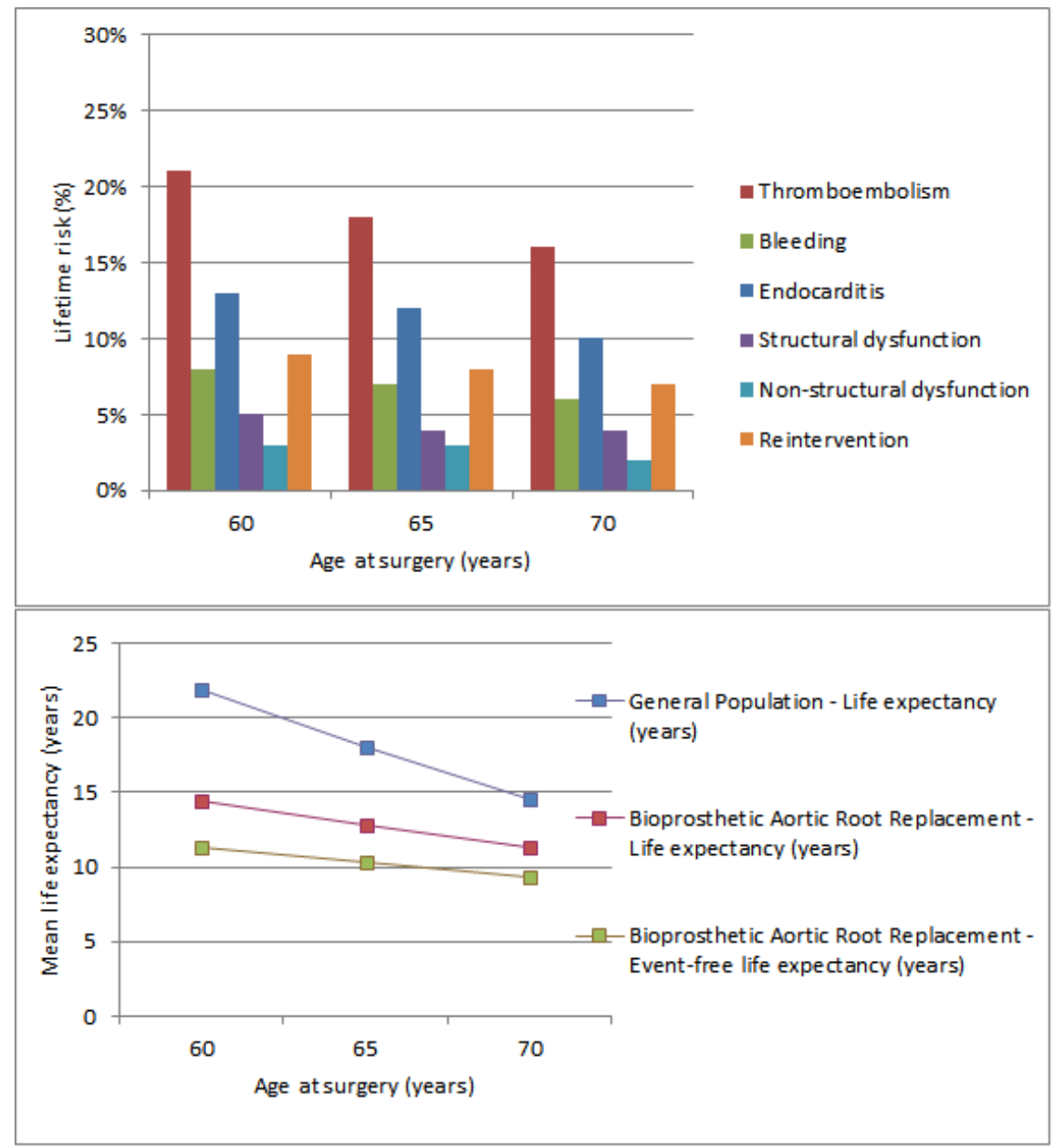

Figure 2. Microsimulation-based life expectancy and lifetime risk of valve-related morbidity for 60,65 and 70 years old patients.

\section{Hosted file}

Table 1.pdf available at https://authorea.com/users/377151/articles/509018-clinical-outcomeafter-bioprosthetic-aortic-root-replacement-a-meta-analysis-and-microsimulation-model

\section{Hosted file}

Table 2.pdf available at https://authorea.com/users/377151/articles/509018-clinical-outcomeafter-bioprosthetic-aortic-root-replacement-a-meta-analysis-and-microsimulation-model

\section{Hosted file}

Table 3.pdf available at https://authorea.com/users/377151/articles/509018-clinical-outcomeafter-bioprosthetic-aortic-root-replacement-a-meta-analysis-and-microsimulation-model

\section{Hosted file}

Table 4.pdf available at https://authorea.com/users/377151/articles/509018-clinical-outcomeafter-bioprosthetic-aortic-root-replacement-a-meta-analysis-and-microsimulation-model

\section{Hosted file}


Figure 1.pdf available at https://authorea.com/users/377151/articles/509018-clinical-outcomeafter-bioprosthetic-aortic-root-replacement-a-meta-analysis-and-microsimulation-model

\section{Hosted file}

Figure 2.pdf available at https://authorea.com/users/377151/articles/509018-clinical-outcomeafter-bioprosthetic-aortic-root-replacement-a-meta-analysis-and-microsimulation-model 